\title{
ANALYSIS OF EXTERNAL FACTORS INFLUENCES ON AVIATION EVENTS CAUSED BY THE HUMAN FACTOR
}

\author{
Vitaliy LARIN, Anastasia YEMELYYANOVA \\ National Aviation University of Ukraine, 1, Liubomyra Huzara ave. Kyiv, Ukraine, 03058 \\ Volodymyr MASLOV* \\ V. Lashkaryov Institute of Semiconductor Physics NAS of Ukraine, 41, Nauki ave., Kyiv, Ukraine, \\ 03028 \\ *Corresponding author. E-mail: vpmaslov@ukr.net
}

\begin{abstract}
In manuscript considered human factor in traffic control. It was showed, that we cannot highlight one factor, which most influence to traffic controller or pilot. We need to consider a group of factors. We performed analysis of the influence of human factor in aviation shows that the latter should comprise several external factors, namely: intensity of traffic, weather conditions and magnetic storms, which are related with solar activity and unpredictability of magnetic storms caused by arising sunspots, as well as with putting into operation the new models of airplanes, to avionics of which pilots are forced to adapt for a definite period and acquire their own experience in operation with this model of aircraft.
\end{abstract}

Keywords: aviation events; human factor; Sun activity; aviation medicine

\section{INTRODUCTION}

The so-called "human factor" (HF) is most often defined as a complex of main human social qualities that have been formed in society. However, up to date there is no commonly adopted definition of this notion, since different interpretations of it are inherent to many fields of knowledge and spheres of professional activity. Therefore, when considering HF it is necessary to analyze interaction between the following ergogenics: individual, operating and organizational, which directly influences on human productivity and capability of a man to unmistakably perform his professional activity.

The transportation branch is one of the most dependent on HF. In the motor transport, human mistakes result in $90 \%$ of all accidents. In this case, $57 \%$ of these accidents are caused by human mistakes, which are practically the only factor that could lead to the accidents [1]. Concerning the railway, statistics indicates that the most frequent reason of accidents in it is mistaken human actions. Their fraction in the total volume of transport incidents reaches $90 \%$ [2].

The crew of aircraft is, first of all, people that possess their own psycho-emotional features, therefore, one can say about the necessity of effective organization of relations inside the team, since these relations influence on quality and trouble-free operation of the aircraft. Investigations have shown that the largest number of emergency situations is caused not by technical failures but human mistakes [3]. They define approximately $70 \%$ of plane crashes.

To date, the nature and role of ATC personnel in aviation accidents and incidents has yet to be fully examined. Human error has been cited as a major factor in the majority of aviation accidents and incidents [4]. To date, however, the causal role of aircrew errors has received the bulk of the attention by both air safety investigators and human factors researchers. As with most aviation accidents today, many of these occurrences have not been due to faulty control equipment, but rather to human error, including mistakes made by air traffic controllers [5]. 


\section{REASONS FOR HUMAN MISTAKES}

There are two main kinds of HF manifestation in the process of making an erroneous decision or performing actions: mistake and breach.

1. The mistake is an action or decision varying from the right algorithm.

2. The breach is intentional deviation from a rule or procedure.

To a considerable degree, the mistakes or blunders are actions that were not planned beforehand, i.e., they are unintentional. They arise in the process of fulfilling ordinary tasks. Usually, this kind of mistakes takes place in technological processes with a high level of automation. These mistakes cannot be eliminated by training the personnel, but some improvements of the system can decrease their probability and provide higher stability of this system to the mistakes.

Another kind of mistakes is related to judgement and making a decision, when the man makes wrong actions and considers them as the right ones (Table 1,2). As a rule, it takes place in situations when the man does not know how to perform the task in a right manner or because of new or unexpected conditions, or in the case of necessary knowledge deficiency and lack of competence. These mistakes can be avoided by training based on right procedures.

The breaches differ from the abovementioned mistakes by their intentionality [6].

The aim of this paper was to analyze the effect of various external factors that took place in air disasters caused by HF during 2000 - 2019 years.

So, in all the transport branches that are considered above we deal with a high percent of incidents (transport accidents, nonfatal and fatal ones, emergencies) when the man caused them. With account of it, in every sphere of human activity one should be aimed to eliminate these problems (including $\mathrm{HF}$ ) or, at least, to lower their influence. But HF is not a simple malfunction like to disrepair of some equipment, it is more profound notion that cannot be excluded in toto. Therefore, they always try to minimize its influence. It is just the aviation field where they try to understand and control HF more often than in other fields, as it can be seen from statistical data.

Table 1 Reasons for human mistakes that depend only on the man [7]

\begin{tabular}{|l|l|}
\hline Kinds of reasons & Content of the reason \\
\hline Professional qualities & $\begin{array}{l}\text { Low level of operator's knowledge. Deficiencies in the development and } \\
\text { realization of professional skills and abilities. Absence or lack of professional } \\
\text { experience. Unpreparedness to apply special ways for supporting the capacity } \\
\text { to work }\end{array}$ \\
\hline Personal qualities & $\begin{array}{l}\text { Unfavorable directivity to a specific operator's profession. Low attitude to } \\
\text { perform a specific task. Deficiencies in development of professionally } \\
\text { important psychic qualities. Unfavorable features of personality (quick temper, } \\
\text { lack of restraint, nervousness, slow response, aggressiveness, depression, } \\
\text { diffidence, anxiety, dishonesty, laziness, delusiveness, etc). Unfavorable } \\
\text { psychic conditions (incongruity of affect, low readiness, insufficient } \\
\text { attentiveness, phobias, dominant conditions, tiredness, stress) }\end{array}$ \\
\hline $\begin{array}{l}\text { Mental-and-ethical } \\
\text { qualities }\end{array}$ & $\begin{array}{l}\text { Insufficient moral-ethic maturity. Low single-mindedness. Lack of discipline, } \\
\text { carelessness, irresponsibility, dishonesty, etc. }\end{array}$ \\
\hline $\begin{array}{l}\text { Physiologic } \\
\text { somatic features }\end{array}$ & $\begin{array}{l}\text { Development of acute or exacerbation of chronic diseases. Biorhythm } \\
\text { disturbance. Mixed or sinistral profile of functional asymmetry of pair organs. } \\
\text { Unfavorable functional conditions (loss of consciousness, vestibular } \\
\text { disturbances, etc). }\end{array}$ \\
\hline Physical features & $\begin{array}{l}\text { Deficiencies in physical strength, dexterity, speed and endurance. Unfavorable } \\
\text { anthropometric or biomechanical features. }\end{array}$ \\
\hline
\end{tabular}


Table 2. Classification of reasons for human mistakes that depend only on external factors [7]

\begin{tabular}{|l|l|}
\hline Kinds of reasons & Content of reasons \\
\hline $\begin{array}{l}\text { Ways for operation (elements } \\
\text { of workplace) }\end{array}$ & $\begin{array}{l}\text { Nonrational layout of devices. Deficiencies of information coding. } \\
\text { Unsatisfactory legibility of texture. }\end{array}$ \\
\hline $\begin{array}{l}\text { Ways for displaying } \\
\text { information }\end{array}$ & $\begin{array}{l}\text { Insufficient time for signal influence. Breach of ergonomic } \\
\text { requirements concerning brightness, contrast, etc. }\end{array}$ \\
\hline Operator control & $\begin{array}{l}\text { Deficiencies in construction (dimensions, shape, character of the } \\
\text { surface) Breach of spatial relationships (mutual placement, } \\
\text { grouping). Non-rational loading, inertness, amplitude of } \\
\text { displacement, etc. }\end{array}$ \\
\hline $\begin{array}{l}\text { Conditions for activity (factors } \\
\text { of ambient medium) }\end{array}$ & $\begin{array}{l}\text { Breach of geometrical dimensions for workplace elements, } \\
\text { examination conditions, accessibility etc. Insufficient conditions for } \\
\text { stay (concerning the microclimate, gas content of ambient } \\
\text { atmosphere, visual field illuminance, etc. Breach of ergonomic } \\
\text { requirements to special equipment and work wear. Unfavorable } \\
\text { effect of climatic factors. Intra-group conflicts, psychological } \\
\text { incompatibility. }\end{array}$ \\
\hline $\begin{array}{l}\text { Job content (execution of } \\
\text { actions, operations) }\end{array}$ & $\begin{array}{l}\text { Excess information overloading. Non-optimal ways for performing } \\
\text { actions. Non-rational distribution of functions between a man and } \\
\text { automatic facilities. Too high rate of work or its monotony. }\end{array}$ \\
\hline $\begin{array}{l}\text { Activity arrangement } \\
\text { (regulation, control, provision } \\
\text { of the job) }\end{array}$ & $\begin{array}{l}\text { Non-rational regime of work and rest. Redundant professional } \\
\text { loading per day or week. Wrong developed programs for personal } \\
\text { preparation. Deficiencies in governing and providing this kind of } \\
\text { activity. }\end{array}$ \\
\hline $\begin{array}{l}\text { Doer (methods and criteria for } \\
\text { estimating the operator } \\
\text { condition) }\end{array}$ & $\begin{array}{l}\text { Deficiencies in professional selection of cadres (medical, } \\
\text { psychological). Low efficacy of psychological and medical control } \\
\text { (expert examination). }\end{array}$ \\
\hline
\end{tabular}

\section{ANALYZING THE MISTAKES}

As said above, all that is included into the sphere of human responsibility brings an imprint of HF. And the air traffic controller profession is not an exception to rule, but by the contrast it is a bright example for this case. The air traffic controller is an aviation worker who provides control and service of air traffic from his workplace in the control unit.

His main task is to provide safety and ordered traffic of various aircrafts. It is not in vain called as one of the most difficult and stressful works in the world. This profession is very dangerous and requires responsibility, since it is related with complex equipment and human lives.

A conception about the system of psychic processes can serve as a basis for analyzing the mistakes. Figure 1 shows the classification of mistakes in the operator activity, which can be made by the air traffic controller.

Pilots work in very hard labor conditions. Therefore, we consider the cumulative contribution caused by mistakes of both traffic controllers and pilots.

The central place in the problem of personnel reliability is occupied by psychological readiness to the work in variable conditions. The level of this readiness is influenced by: professional competence (knowledge, ability, habits of work); functional condition (tiredness, attentiveness, speed of response, health status); personal psychological qualities (responsibility, decency, self-control); socialpsychological climate in the working team (consistency of acts, proneness to conflicts, social values); social conditions for work and life of the personnel (equipment of the workplaces, level of automation etc.) [9]. 


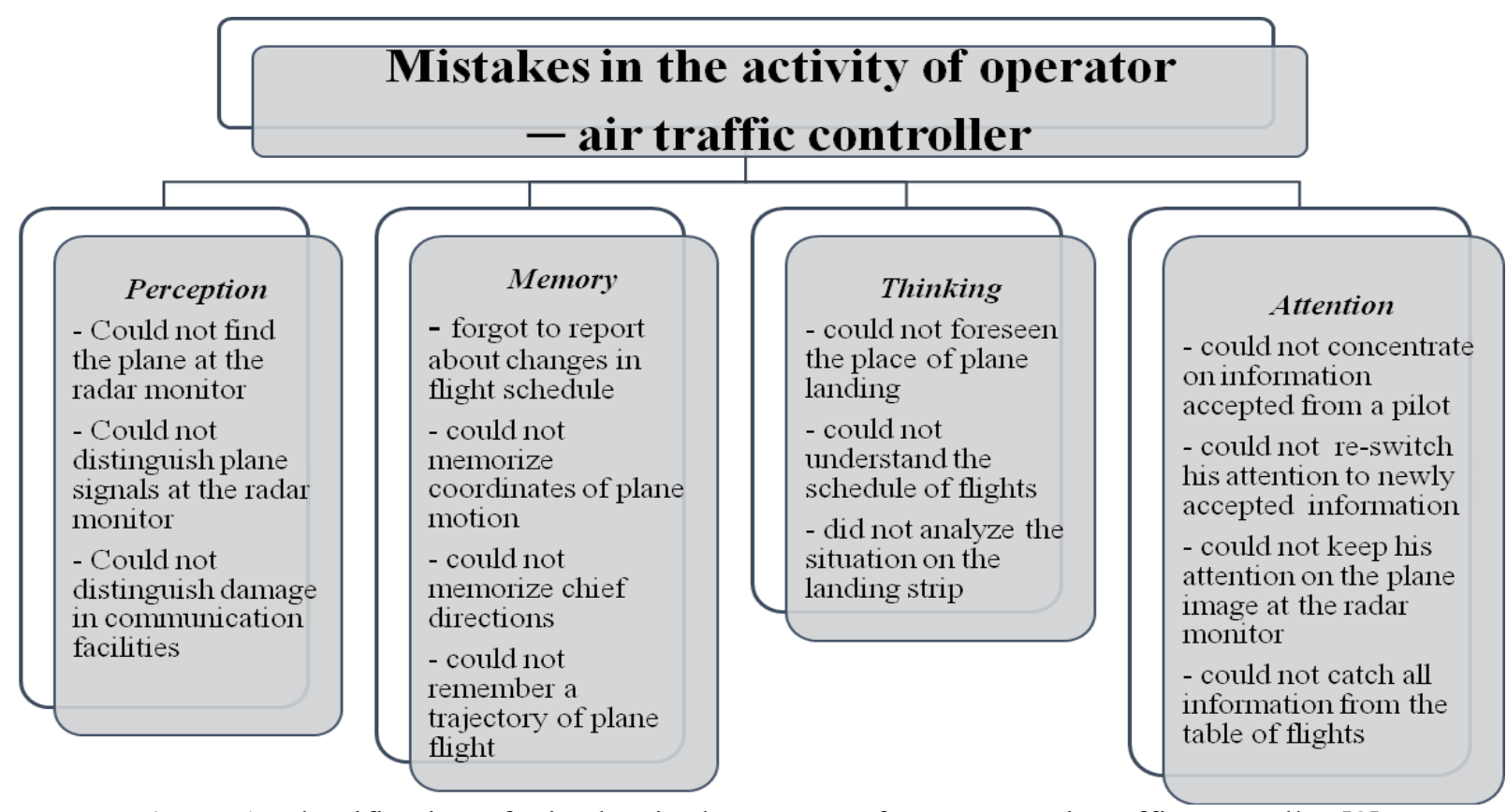

Figure 1. Classification of mistakes in the activity of operator - air traffic controller [8]

In aviation, the influence of man on results of functioning of any system plays a considerable role. The man, being in his workplace, can make mistakes, make insufficiently grounded decisions, i.e., be a reason for displaying HF. Since behavior of a man is very complex, his mistakes are not predicted. And it is these mistakes that can be caused by existence of a lot of factors influencing on activity of air traffic controller.

And among them: important character of this work, stressful moments in specific hours of saturation or very complex conditions in air, overflow of air space, continuous necessity to concentrate attention, variable operating schedule, as well as awareness of that your mistake can result in disaster.

The practice of investigation of aviation events indicates availability of a great amount of reasons, especially at the first stages of these investigations, therefore analyzing and researching them are very difficult and multi-factor task. From the methodical viewpoint, it is commonly adopted to represent all unfavorable factors (reasons) in the form of three groups: failures of aviation equipment, mistaken actions of aviation personnel and unfavorable external conditions [10].

Any incident is quintessence of mistakes. When performing investigations of an aviation event, there can be found those mistakes that were made at various stages, namely: training of pilots, maintenance of the airplane, usage of low-quality fuel, deficiencies in aeronavigation service and other moments.

There took place implementation of new technologies and development of aviation science in whole, however, in parallel with lowering the aviation events caused by failures of aviation equipment, the fraction of events related with mistaken actions of aviation personnel, especially the air crew one, was increased.

The preliminary hypothesis for explaining this fact was that the increase in the amount of aviation traffic related to the development of tourism, increasing cargo transportation, general globalization and specialization of production results in the enhanced load on pilots and air traffic controllers, and to the increased accident rate, respectively.

But the analysis of transportation traffic intensity (expressed in passenger-kilometer units) showed the impetuous growth by $7.9 \%$ up to 2017 year and insignificant drop of this growth during 2017 2019 years. At the same time, the amount of disasters during this period demonstrated an uneven distribution and availability of several maxima and minima for this period (Figure 2). It means that the amount of disasters is influenced not only by the intensity of flights but by some other factors. 


\section{RESULTS AND DISCUSSION}

After performing investigations concerning interrelation between the growth of traffic intensity and possible increase in the amount of disasters, we obtained the result that does not confirm the previous hypothesis of above interrelation. It would be logical to guess that when the intensity of flights grows, the tension for aviation personnel grows, too. And this tension can serve as a premise for occurrence of disasters or incidents [11-13]. However, the built plot for the amount of disasters/incidents shows that this value is unstable (Figure 2).

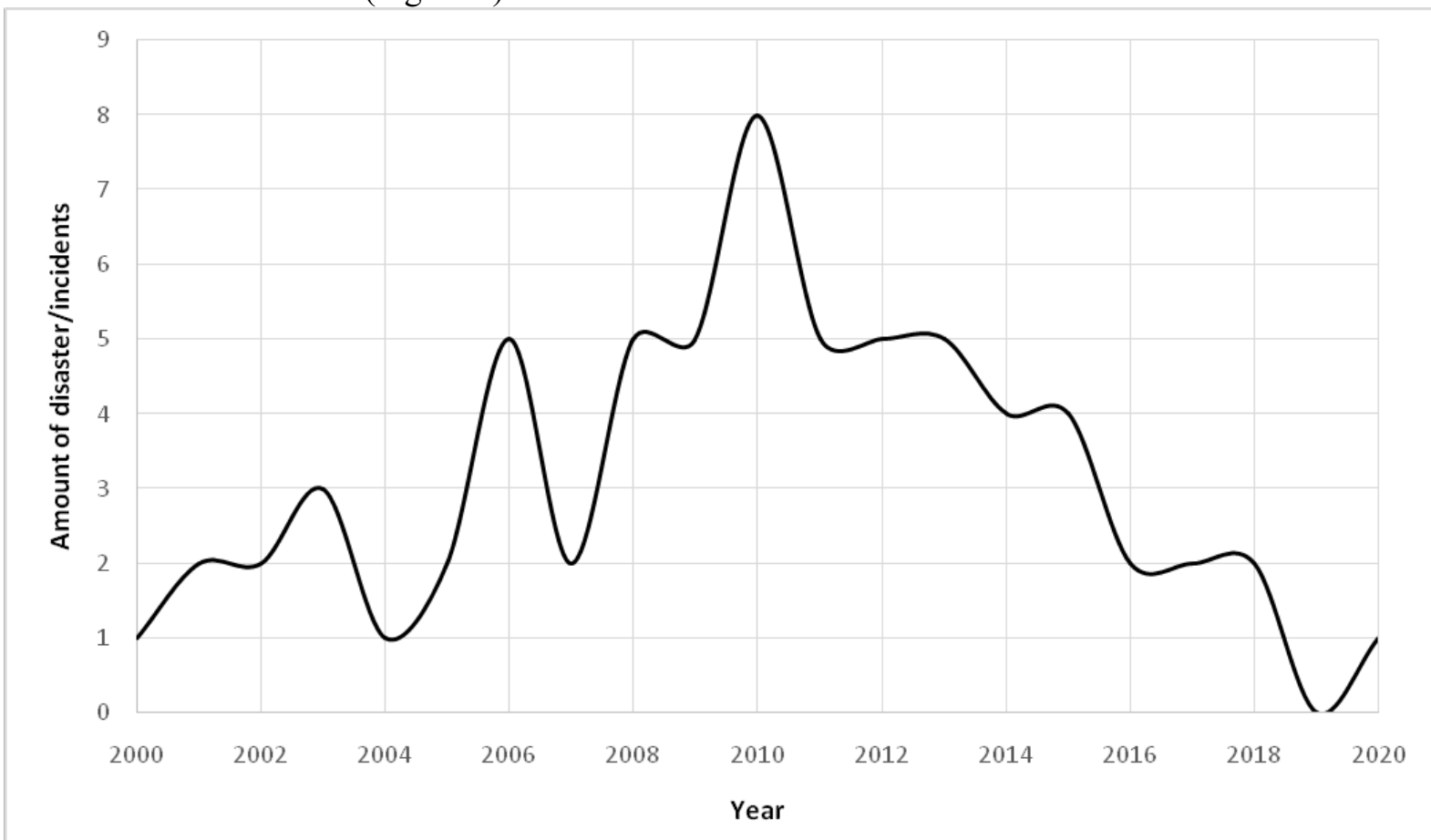

Figure 2. Amount of disasters/incidents during the period $2000-2020$ years caused by air traffic controllers and pilots (in the world)

So, this theory of interrelation is not absolutely true. It means that one should search and be based on some other important factor, which rather has a periodical character that influences on people. Thereof, it was made an assumption about the Sun effect [14].

For example, it is adopted to put a clock forward/back twice a year to improve interaction between a man and Sun. May be this factor also is one of the reasons influencing the aviation personnel and leads to air disasters? Considering this matter, we built the plot of correlation between the Sun activity and amount of air disasters during several years.

Using the data about amount of incidents and Sun activities, we obtained the following plot (Figure 3).

Juxtaposition of both plots shows that the increase in amount of disasters in 2005 corresponds to lowering the sunspot activity, while the peak of air disasters in 2011 coincides with the maximum of sunspot activity and magnetic storms related to this phenomenon. Beside the predictable periodic solar activity, the magnetic storms can arise being caused by unpredictable sunspots. It is also necessary to take into account weather conditions that are able to make a serious effect on the general state of personnel. In addition, one can conclude that this factor is not the main one in occurrence of disasters but has its place among other factors. 


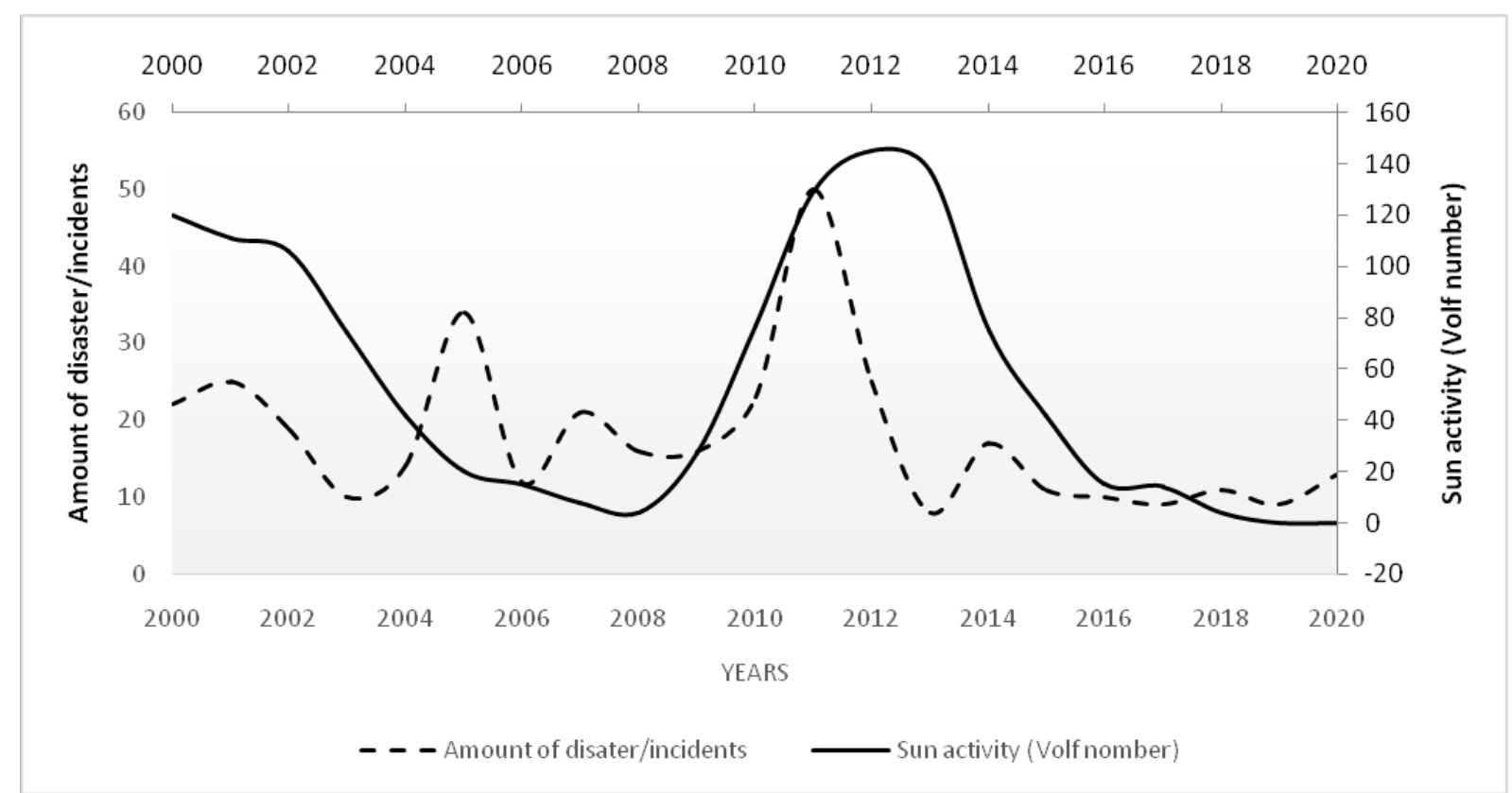

Figure 3. Correlation plot for the amount of disasters/incidents and Sun activity

As seen from Fig. 3, during 2005-2009 years the amount of plane crashes had its minimum, which coincides with the minimal solar activity. In addition, one factor more can play its role enhancement of requirements and controlling functions to the health of flight personnel from the side of aviation medicine.

Another possible factor can be putting into operation several new models of airplanes, for instance, Boeing 737 Max (the most widely spread new aircraft related to some disasters), to avionics of which the pilots adapt for a definite period and acquire their own experience of governing this plane.

\section{CONCLUSIONS}

The performed analysis of the influence of human factor shows that the latter should comprise several external factors, namely: intensity of traffic, weather conditions and magnetic storms, which are related with solar activity and unpredictability of magnetic storms caused by arising sunspots, as well as wih putting into operation the new models of airplanes, to avionics of which pilots are forced to adapt for a definite period and acquire their own experience in operation with this model of aircraft.

\section{References}

[1] Shappell, S. - Detwiler, C. - Holcomb, K. - Hackworth, C. - Boquet, A. - Wiegmann, D. Human Error and Commercial Aviation Accidents: A Comprehensive, Fine-Grained Analysis Using HFACS. Final report. 2006. 24 p. http://libraryonline.erau.edu/online-full-text/faa-aviation-medicinereports/AM06-18.pdf

[2] Papadimitriou, E., Schneider, Ch., Tello, J.A., Damen, W, Vrouenraets, M.L., Broeke, A. Transport safety and human factors in the era of automation: What can transport modes learn from each other? Accident Analysis and Prevention. 2020. Vol. 144, [105656]. https://doi.org/10.1016/j.aap.2020.105656

[3] Sadykov, G.N. Psychological content of human factor in aviation. Gumanitarnyi chasopys. 2014. No 4. P. 101-108.

[4] Pape, A.M. - Wiegmann, D. A. - Shappell, S. Air traffic control (atc) related accidents and incidents: a human factors analysis. In: 11th International Symposium on Aviation Psychology.

Columbus, OH: The Ohio State University. 2001 
[5] Shappell, S.A., Wiegmann, D.A. The human factors analysis and classification system (HFACS) (Report Number DOT/FAA/AM-00/7). Federal Aviation Administration, Washington DC. 2000.

[6] Understanding Human Factors: a guide for the railway industry. Rail Safety and Standards Board. 2008. $218 \mathrm{p}$.

[7] O'Connor, K., Stevens, R. Professional Engineering Work. Academia. 2008. P. 119-137

[8] Goeters K-M. Aviation Psychology: Practice and Research. Ashgate publishing. 2017, 408 p. https://doi.org/10.4324/9781315261843

[9] Shanmugam A., Robert T. P. Human factors engineering in aircraft maintenance: a review. Journal of Quality in Maintenance Engineering. 2015. Vol. 21. No. 4. P. 478-505 DOI:10.1108/JQME-05-2013-0030

[10] Xue Y, Fu G. A modified accident analysis and investigation model for the general aviation industry: Emphasizing on human and organizational factors. Journal of Safety Research. 2018. Vol. 67. P. 1-15 DOI: $10.1016 /$ j.jsr.2018.09.008

[11] The World of Air Transport in 2019. ICAO Annual Report 2019. Online available: https://www.icao.int/annual-report-2019/Pages/the-world-of-air-transport-in-2019.aspx

[12] The World of Air Transport in 2017. ICAO Annual Report 2017. Online available: https://www.icao.int/annual-report-2017/Pages/the-world-of-air-transport-in-2017.aspx

[13] ICAO Annual Report of the Council - 2008. Online available: https://www.icao.int/publications/Documents/9916_en.pdf

[14] Balogh, A. - Hudson H.S. - Petrovay K. - von Steiger R. Introduction to the Solar Activity Cycle: Overview of Causes and Consequences. In: Balogh A., Hudson H., Petrovay K., von Steiger R. (eds) The Solar Activity Cycle. Space Sciences Series of ISSI. Springer, New York, NY. 2015. Vol.53. P.1-15 https://doi.org/10.1007/978-1-4939-2584-1_1

Received 06, 2021, accepted 07, 2021

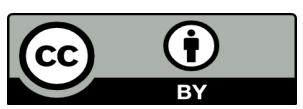

Article is licensed under a Creative Commons Attribution 4.0 International License 